\title{
Amamentação: dificuldades enfrentadas pelas puérperas primíparas no alojamento
}

\section{conjunto}

\author{
Breastfeeding: difficulties faced by primiparous mothers in rooming-in \\ Lactancia materna: dificultades que enfrentan las madres primíparas en el alojamiento conjunto
}

Recebido: 09/11/2021 | Revisado: 14/11/2021 | Aceito: 18/11/2021 | Publicado: 20/11/2021

\author{
Ítala Camila Fraga da Cunha Nepomuceno \\ ORCID: https://orcid.org/0000-0001-6014-2623 \\ Faculdade Interamericana de Porto Velho, Brasil \\ E-mail: ytalacamila20@ hotmail.com \\ Edlaine Souza Medeiros \\ ORCID: https://orcid.org/0000-0001-6014-2623 \\ Faculdade Interamericana de Porto Velho, Brasil \\ E-mail: edlaine.medeiros.2016@gmail.com \\ Adriane Bonotto Salin \\ ORCID: https://orcid.org/0000-0003-1200-0887 \\ Faculdade Interamericana de Porto Velho, Brasil \\ E-mail: adrybonotto@gmail.com
}

\begin{abstract}
Resumo
O estudo tem como objetivo avaliar as dificuldades enfrentadas pelas puérperas primíparas no processo de amamentação no Alojamento Conjunto em uma Maternidade de Porto Velho/RO. Para a realização optou-se por uma pesquisa de campo com escopo exploratório, descritivo com abordagem qualitativa. A pesquisa foi realizada na Maternidade Municipal Mãe Esperança com 15 puérperas primíparas, de acordo com os critérios de inclusão e exclusão, com uso da técnica entrevista com roteiro semiestruturado, considerando os aspectos éticos e legais da pesquisa determinados pela Resolução 466/12 do Conselho Nacional de Saúde/Ministério da Saúde. Os dados foram transcritos na íntegra para análise, respeitando o sigilo das informações. Mediante as falas, foi possível identificar que as puérperas não receberam de forma satisfatória durante o pré-natal as informações necessárias sobre a amamentação, apresentaram dificuldades e não souberam esclarecer os benefícios desta prática. Destacou-se que dentro do Alojamento as puérperas receberam orientações que foram essenciais para darem continuidade ao ato de amamentar. Conclui-se que se faz necessário fomentar tal assunto a fim de aumentar as discussões e incentivar o enfermeiro a atuar na educação em saúde desde o pré-natal até a fase puerperal dentro do Alojamento, pois foi identificado a dificuldade que as puérperas no que tange a amamentação e sobre sua relevância.
\end{abstract}

Palavras-chave: Amamentação; Puerpério; Alojamento conjunto.

\begin{abstract}
The study aims to evaluate the difficulties faced by primiparous mothers in the breastfeeding process in Rooming-in at a Maternity Hospital in Porto Velho/RO. For the realization, it was opted for a field research with exploratory scope, descriptive with a qualitative approach. The research was conducted at the Mãe Esperança Municipal Maternity Hospital with 15 primiparous mothers, according to the inclusion and exclusion criteria, using the interview technique with a semi-structured script, considering the ethical and legal aspects of the research determined by Resolution 466/12 of the National Council of Health/Ministry of Health. The data were transcribed in full for analysis, respecting the confidentiality of the information. Through the statements, it was possible to identify that the mothers did not receive the necessary information about breastfeeding satisfactorily during the prenatal period, they had difficulties and were unable to clarify the benefits of this practice. It was highlighted that within the accommodation, the mothers received guidelines that were essential to continue the act of breastfeeding. It is concluded that it is necessary to promote this issue in order to increase discussions and encourage nurses to act in health education from prenatal care to the puerperal stage within the Accommodation, as the difficulty that puerperal women with regard to breastfeeding and its relevance.
\end{abstract}

Keywords: Breastfeeding; Puerperium; Joint accommodation.

\begin{abstract}
o
El estudio tiene como objetivo evaluar las dificultades que enfrentan las madres primíparas en el proceso de lactancia materna en Rooming in a Maternity Hospital en Porto Velho / RO. Para la realización se optó por una investigación de campo con alcance exploratorio, descriptiva con enfoque cualitativo. La investigación se realizó en la Maternidad Municipal Mãe Esperança con 15 madres primíparas, según los criterios de inclusión y exclusión, utilizando la técnica de entrevista con guión semiestructurado, considerando los aspectos éticos y legales de la investigación determinados
\end{abstract}


por la Resolución 466/12. del Consejo Nacional de Salud / Ministerio de Salud Los datos fueron transcritos íntegramente para su análisis, respetando la confidencialidad de la información. A través de las declaraciones se pudo identificar que las madres no recibieron la información necesaria sobre la lactancia materna de manera satisfactoria durante el período prenatal, tuvieron dificultades y no pudieron esclarecer los beneficios de esta práctica. Se resaltó que dentro del alojamiento, las madres recibieron pautas que fueron fundamentales para continuar con el acto de amamantar. Se concluye que es necesario promover este tema con el fin de incrementar las discusiones y alentar a las enfermeras a actuar en la educación en salud desde la atención prenatal hasta la etapa puerperal dentro del Alojamiento, como la dificultad que tienen las puérperas con respecto a la lactancia materna y su relevancia.

Palabras clave: Lactancia materna; Puerperio; Alojamiento conjunto.

\section{Introdução}

A amamentação é responsável pelo bom desenvolvimento do indivíduo, caracteriza-se por ser um ato essencial para compor a alimentação de uma criança nos primeiros meses de vida, devendo ser até o sexto mês de maneira exclusiva, pois o mesmo é rico em vitaminas, carboidratos, proteínas, sais minerais, água e gordura (Moraes et al., 2020).

A recomendação do Ministério da Saúde (MS) é que a amamentação deve ser iniciada logo após o nascimento, uma vez que proporciona diversos benefícios para o binômio, entre eles a prevenção contra doença da infância e fortalecimento do vínculo entre ambos (Brasil, 2019).

Santos et al. (2019) discorrem que processo da amamentação deve ser exclusivo até os seis meses e complementar até 24 meses ou mais, esta recomendação e preconizada com base em resultados de estudos que evidenciam os benefícios dessa prática tanto para as crianças quanto para as mães.

Durante o pré-natal, os profissionais de saúde influenciam diretamente na conduta após o parto, pois eles auxiliam na orientação, encorajamento e desmistificar os tabus existentes (Ferreira, Gomes \& Fracolli, 2018).

No entanto após o parto, no Alojamento Conjunto (ALCON), um setor situado dentro de uma unidade hospitalar, em que os profissionais prestam assistência direcionadas às puérperas e aos Recém-Nascidos (RN), ou seja, são responsáveis por proporcionar este momento de adaptação com a nova fase da puérpera, principalmente quando a mesma é primípara. Este é um momento oportuno para a disseminação de informações, principalmente quanto ao processo de amamentação, suporte emocional, formação de vínculo com o binômio, manejo de cuidados e identificação de possíveis problemas (Mesquita et al., 2019).

Lopes et al. (2020) enfatizam que a enfermagem está ligada diretamente no processo de esclarecimentos e orientações acerca da amamentação, para que sejam colocadas em prática, respeitando a individualidade de cada lactante, ou seja a atuação dessa equipe no processo de amamentação é de fundamental importância, uma vez que é possível identificar as dificuldades na amamentação dos RNs.

Frente às considerações relacionadas ao processo de amamentação e dificuldades vivenciadas no ALCON, surge a questão norteadora que conduzirá esta pesquisa: quais são as dificuldades vivenciadas pelas primíparas no puerpério imediato sobre a amamentação?

Nesta perspectiva, o estudo tem por objetivo avaliar as dificuldades enfrentadas pelas puérperas primíparas na amamentação dentro do Alojamento Conjunto em uma Maternidade de Porto Velho/RO.

\section{Metodologia}

Trata-se de uma pesquisa de campo com escopo exploratório, descritivo de abordagem qualitativa, com o objetivo de avaliar as dificuldades enfrentadas pelas puérperas primíparas no processo de amamentação no Alojamento Conjunto em uma Maternidade de Porto Velho/RO. 
A pesquisa de campo procede à observação de fatos e fenômenos exatamente como ocorrem na realidade, coleta de dados referentes aos mesmos e, finalmente, à análise e interpretação desses dados, com base numa fundamentação teórica consistente, objetivando compreender e explicar o problema pesquisado (Minayo, 2014).

Em se tratando de pesquisa exploratória, Severino (2016) menciona que essa metodologia busca levantar informações sobre um determinado assunto, delimitando-as para que o objetivo seja alcançado.

Volpato (2015) menciona que a pesquisa descritiva permite descrever algo caracterizando de forma variável, onde o pesquisador tem a opção de descrever mais de uma variável, fazendo desta forma um único estudo.

A pesquisa qualitativa segundo Creswel (2014) é uma abordagem que busca compreender o significado do que é apresentado, sendo realizado através de entrevistas, diálogos ou registros, por exemplo, sendo de forma interpretativa e naturalística.

Para seleção amostral, foi utilizada a amostragem por conveniência do tipo não probabilística, dos quais foram convidadas a participar de maneira voluntária do estudo um número de 15 puérperas primíparas, atingindo assim a totalidade de pesquisadas o qual foi proposto inicialmente, considerando os critérios de inclusão e exclusão.

A pesquisa foi realizada a partir dos pressupostos contidos na Resolução 466/12 do Conselho Nacional de Saúde/ Ministério da Saúde, que aprova as diretrizes e normas regulamentadoras de pesquisas envolvendo seres humanos e (Resolução n. 510 , de 07 de Abril de 2016 do Conselho Nacional de Saúde/Ministério da Saúde). A pesquisa iniciou-se mediante autorização prévia da direção da maternidade e aprovação pelo Comitê de Ética e Pesquisa (CEP) da União Educacional do Norte Ltda (UNINORTE) em 10 de setembro de 2021, sob o parecer n 4.963.162 e CAAE: 4 8219321.7.0000.8028.

No primeiro momento, houve um contato prévio na Maternidade Municipal Mãe Esperança, com intuito de adequar um local específico e reservado para a realização da pesquisa, bem como ter acesso as puérperas primíparas admitidas no ALCON.

Após a autorização, as pesquisadoras retornaram à unidade e iniciaram a coleta de dados, as puérperas foram abordadas. As participantes que aceitaram voluntariamente participar, receberam informações sobre o estudo e foi assegurado a todas as participantes o sigilo das informações e em hipótese alguma seriam identificadas.

Foram incluídas na pesquisa puérperas primíparas maiores de 18 anos, internadas com o RN no ALCON da Maternidade Municipal Mãe Esperança (MMME), no puerpério imediato (a partir de 6 horas após o parto), que estavam amamentando exclusivamente, que concordaram em participar da pesquisa, assinaram o Termo de Consentimento Livre e Esclarecido (TCLE) e que estavam presentes nos dias da coleta de dados.

Foram excluídas da pesquisa puérperas multíparas, puérperas com RN que estavam no berçário, aquelas que apresentaram contraindicação para a amamentação, puérperas que não se enquadravam no período estipulado pelas pesquisadoras, puérperas que já utilizaram outras estratégias para introdução do leite materno e aquelas que não manifestaram interesse em participar do estudo.

Para coleta de dados foi utilizado de um roteiro semiestruturado, contendo cinco questões para caracterização do perfil obstétrico das participantes do estudo e cinco questões para a identificação das dificuldades vivenciadas no processo de amamentação as quais foram necessárias para responder aos objetivos do estudo, com roteiro norteador e elaborado pelas pesquisadoras, as respostas foram gravadas utilizando um aplicativo de voz do próprio celular denominado Revoice.

Cabe ressaltar que foi garantido o anonimato das entrevistadas, pois seus nomes foram mantidos em sigilo através do uso de pseudônimos utilizando nome de flores (como por exemplo: Petúnia, Camélia, etc). 


\section{Resultados e Discussão}

A amostra final foi composta por 15 puérperas primíparas que estavam sob os cuidados do ALCON, em uma Maternidade de Porto Velho/RO.

As informações principais referentes à caracterização do perfil obstétrico das puérperas, as maiorias encontravam-se na faixa entre 18 e 23 anos, com ensino médio completo, tinham realizado seis ou mais consultas e estavam com IG ente 38 a 40 semanas e a predominância do parto foi por via vaginal.

Corroborando com este estudo, é essencial o acompanhamento durante o pré-natal, podendo ser feita por um enfermeiro, se for de baixo risco e em casos de complicações o enfermeiro intercala as consultas com o médico, onde devem ser realizadas até a $28^{\mathrm{a}}$ semana, mensalmente, da $28^{\mathrm{a}}$ até a $36^{\mathrm{a}}$ semana, quinzenalmente e da $36^{\mathrm{a}}$ até a $41^{\mathrm{a}}$ semana, semanalmente (Brasil, 2018).

Quanto a via de parto, é possível destacar que o vaginal vem diminuindo com o passar dos anos, onde entre 2010 a 2019 foi observado uma diminuição de $13 \%$ nesta via e um aumento de 9,2\% no parto cesariano (Brasil, 2020).

Rocha e Ferreira (2020) afirmam que o parto vaginal quando acontece no setor público geralmente não é por escolha e sim indicação médica e que ocorre predominantemente entre 18 a 30 anos.

\subsection{Orientações sobre amamentação na consulta de pré-natal}

Guimarães et al. (2018) afirmam que essa discussão deve ser realizada a cada consulta de pré-natal, sendo este um local oportuno para esclarecimento de dúvidas e orientações, principalmente no que concerne a nutrição do bebê, para que sejam minimizadas as chances de interrupções precoce da amamentação.

Corroborando ainda sobre isso, o enfermeiro atua como educador e facilitador no processo de amamentação, uma vez que estas ações em saúde são indispensáveis para abolir as inseguranças e obstáculos que interferem na amamentação (Rocha et al., 2020).

Ao abordar sobre as orientações repassadas pelo enfermeiro nas consultas de pré-natal referente ao processo de amamentação e os impactos que surtiriam no puerpério, pode-se observar nas falas a seguir a precariedade das informações durante este período tão importante para a mulher:

\footnotetext{
" Não recebi no pré-natal não, eu recebi só na maternidade"' (Antúrio).

"Não no pré-natal não, quando eu passei pela pediatra é que fui orientada sobre isso'” (Moreia).
}

O profissional durante a consulta de PN deve ter habilidade para comunica-se com eficiência, além de tornar a consulta um momento de escuta sobre anseios, deve dialogar e provocar reflexões sobre os principais aspectos da amamentação, incluindo tempo adequado, possíveis complicações que possam enfrentar durante a lactação, mostrando os benefícios para a saúde do binômio, quando o aconselhamento for bem dialogado ajuda a gestante na tomada de decisões, além de estabelecer confiança no profissional e garantir sucesso na amamentação exclusiva, pois a diminuição do conhecimento e/ou mitos acerca do amamentação pode interferir diretamente na amamentação logo levando ao desmame precoce (Barreto $e t$ al., 2021).

Gupta et al. (2017) reforçam que em relação ao aleitamento materno o grupo familiar pode interferir nas escolhas, principalmente se tratando das primíparas, pois mediante as suas próprias experiências levam para a lactante dúvidas e anseios quanto a este processo, por isso a importância do enfermeiro neste contexto de orientação. 
A família pode ser a grande responsável por influenciar negativamente no AM, pois afirmam que o leite é insuficiente, a deficiência de conhecimento, nível baixo de escolaridade, situação financeira e emocional da família e a falta de incentivo e educação no período pré-natal, pós-parto e puerpério corroboram com a interrupção do AM (Moraes et al., 2020).

A qualidade da assistência durante o pré-natal tem impacto direto nos indicadores de saúde, onde a ausência de orientações pode refletir negativamente para o binômio (Mayor et al., 2018).

Beyene, Liben e Arora (2019) relatam que a consulta de pré-natal é o momento ideal para identificar os pontos negativos e trabalhar neles para evitar a desistência da amamentação e outras problemáticas, usando a orientação como seu principal aliado.

Observa-se que as puérperas não receberam informações suficientes e necessárias em relação a amamentação, tornando o tema uma lacuna para este público e mais vulneráveis a desistência o que pode ser evidenciada ainda nas falas:

'A minha enfermeira me informou, mas foi pouca coisa, só falou que até seis meses eu poderia amamentar sem dar água ou outro leite, aí procurei na internet" (Cravo).

'Eu vim receber mesmo foi aqui na maternidade, no pré-natal era ressaltado só a importância'" (Calêndula)

Rodrigues et al. (2020) afirmam que o ato de amamentar é um momento oportuno e deve ser visto de forma individual, pois cada um tem suas vivências e realidades diferentes, onde o profissional de enfermagem deve adotar condutas de apoio e incentivo. A enfermagem, em especial atuam na promoção, onde a orientação é imprescindível para o sucesso no ato de amamentar (Al-Nuaimi \& Ali E-Hatem, 2019).

Durante o processo de amamentação, as influências externas estão ligadas nas condutas a serem tomadas pelas mulheres, sendo as redes sociais o meio mais utilizado na disseminação de informações, onde são necessárias as consultas para orientar da melhor forma possível as puérperas (Skelton et al., 2018).

Prevedello, Dotto e Santos (2020) afirmam que a utilização de novas tecnologias de informação e comunicação tem crescido nos últimos tempos, pois atualmente o mundo está vivenciando a era da internet. Por outro lado, observa-se uma enorme rede de notícias sem embasamentos científicos, o que proporciona uma dificuldade na disseminação da informação correta.

Em um estudo realizado com puérperas, Dewanti et al. (2019) concluíram que o meio tecnológico apresenta também desvantagens, pois a maioria referiu sobrecarga de informações e desvio da ideia origem, pois muitas vezes mudavam o conceito em meio ao que achavam vinculados na internet.

\subsection{Benefícios da amamentação para o binômio}

Aleitar é um processo fisiológico e natural, é a forma mais saudável adequada para alimentar e proteger o RN, ou seja, o leite humano constitui o alimento mais completo e equilibrado, nele estão presentes componentes que suprirão todas as precisões nutricionais e de desenvolvimento nos seis principais meses de vida, além de contribui para construção do sistema imunológico (Barreto et al., 2021).

Santos e Meireles (2021) discorrem que o leite materno além de fornecer aporte nutricional, uma vez que contém substancia nutritiva, vitaminas, minerais, gorduras, açúcares e proteínas, exerce ação na imunidade e defesa, é benéfico para as mães, a amamentação fortalece vínculo afetivo entre binômio, favorece a involução uterina, diminuir o risco de hemorragia pós-parto e desta forma o risco de anemia materna. A amamentação não fica restrita apenas ao binômio, gera implicações para a sociedade, pois uma vez a criança adequadamente nutrida provoca repercussões na redução dos índices de morbimortalidade neonatal e infantil ocasionadas por doenças comuns na infância. 
Durante a coleta, foi possível identificar que a maioria das puérperas não sabiam identificar os benefícios de forma clara, apresentando maior dificuldade quando relacionadas as vantagens na amamentação para elas, como foi confirmado nas falas a seguir:

"É importantíssimo para o bebê, para o desenvolvimento dele e para mim e tudo, pois estou alimentando minha princesa" (Cravina).

" Muito importante porque o leite e cheio de vitaminas agora para mim não sei não a importância"' (Cravo).

"Importante para ela para não ficar doente e crescer saudável, agora para mim eu não sei não qual seria o beneficio"' (Hibisco).

Sardinha et al. (2019) enfatizam que mesmo os profissionais de saúde são fontes seguras para o acesso às informações, contudo, observa-se que as puérperas ainda não sabem identificar a importância da amamentação e por isso se faz necessário intensificar a orientação por parte dos profissionais ainda no pré-natal.

Em um estudo realizado por Ribeiro et al. (2018) no Ceará com puérperas no alojamento, evidenciaram que as mulheres ainda possuem conceitos errôneos quanto a amamentação e os demais cuidados com o RN, onde $40 \%$ ainda enfatizaram que não sabiam que a amamentação era exclusiva até os seis meses e os benefícios para ela mesma.

Relacionado aos benefícios para a puérpera, Feitosa, Silva e Silva (2020) afirmam que o ato de amamentar, atua na prevenção de câncer de mama e útero, auxilia na involução uterina após o parto, diminuição do sangramento e perda de peso. Segundo Moreira et al. (2019) outros benefícios podem ser destacados também, como por exemplo, a formação de vínculo entre o binômio e fortalecimento da imunidade, onde é essencial a presença do enfermeiro nessas orientações e incentivo à puérpera.

Segundo Vieira et al. (2017) o processo de lactação é uma das condições biológicas imprescindíveis e antecede a interação entre binômio, ou seja, o processo de amamentar não é apenas alimentar, constitui um processo interativo entre a mãe e o filho, corrobora com a formação do vínculo afetivo entre eles, e assim favorecendo uma melhor qualidade de vida para ambos.

De acordo com Santos et al. (2019) os bebês nascem com imaturidade principalmente do sistema imunológico e gastrointestinal, onde é essencial ofertar apenas o leite materno exclusivamente até os seis meses, evitando quaisquer tipos de alimentos ou líquidos neste período, pois podem aumentar a probabilidade de desenvolver problemas digestivos, respiratórios ou renais. A parte intelectual da criança também é beneficiados com a amamentação exclusiva, por isso a necessidade desta prática (Arantes et al., 2020).

A amamentação para a criança é fundamental para a prevenção de doenças secundárias como, por exemplo, a diarreia, otite e pneumonia, além do mais, os movimentos do ato de sucção auxiliam a mastigação, na fala, dentição e respiração. Por isso a importância do enfermeiro orientar durante a consulta de pré-natal a amamentação da maneira correta (Brasil, 2019).

Monteiro (2017) corroboram com autores supracitados e descrevem que somado a isso que as puérperas acreditam que o leite materno é fraco por associar o choro do RN com a fome, principalmente nos primeiros dias que desce o colostro que não tem coloração específica, levando a introdução de fórmulas artificiais.

Para Alves et al. (2019) é essencial que sejam desenvolvidas ações voltadas a promoção da amamentação pelos profissionais de saúde com a finalidade de sensibilizar as mulheres quanto a importância do ato de amamentar e seus diversos benefícios, bem como garantir a proteção legal do direito. 


\subsection{Dificuldades vivenciadas no primeiro contato com o ato de amamentar}

Amamentar é uma condição natural, no entanto não é apenas instinto, vai além da decisão de amamentar, além da mãe reconhecer a importância da amamentação para si e para seu filho, na prática nem sempre a ocorre de forma tranquila e comum surgirem dificuldades que, se não sanadas a tempo, podem colaborar para o fracasso do aleitamento materno, sobretudo nas primigestas no puerpério imediato, que podem ser influenciadas por fatores ou condições psicobiológicas, culturais e sociais (Silva et al., 2021).

Destaca-se neste grupo as dificuldades vivenciadas pelas puérperas primíparas, onde a maioria relatou que apresentou e caracterizou o momento como difícil, conforme mencionado nas falas abaixo:

\footnotetext{
“'Bem puxado, porque eu não tinha nem o jeito de pegar e colocar ela'” (Moreia).
}

Durante o processo de aleitação podem surgir situações que dificultam e comprometem a boa prática do aleitamento materno exclusivo, ainda mais quando são primíparas, podendo levar ao desmame precoce ou a introdução de complementações de forma precoce aos neonatos, um dos pontos levantados seria a pega incorreta (Moraes et al., 2020).

O posicionamento inadequado no ato da amamentação configura como uma dificuldade na continuidade do processo de aleitamento materno, pois através deste problema, as fissuras mamilares surgem e acabam interrompendo de forma precoce a amamentação (Ferreira et al., 2020).

Leão et al. (2021) em seu estudo realizado com puérpera na Maternidade em Rondônia, evidenciaram que cerca de $60 \%$ das entrevistadas, relataram que não conseguem posicionar o RN da maneira correta, sendo uma das dificuldades mais relatadas referente a amamentação.

Ainda sobre as dificuldades vivenciadas pelas primíparas:

"'Estou com dificuldade, dói muito, ai estou tentando me adaptar porque dói muito, abriu até fissuras"” (Magnólia).

Segundo Souza, Oliveira e Shimo (2020) estas dificuldades podem estar relacionadas a figura da lactante, como por exemplo o retorno precoce ao trabalho, infecções que contraindicam a amamentação, depressão pós-parto, e ainda mastite, fissuras, insegurança materna quanto ao tempo de amamentar, medo de engasgo, achar que o leite é fraco, dentre outras coisas.

Para Barbosa et al. (2017) as intercorrências mamárias são provenientes da pega e posição inadequadas do bebê no seio da mãe, pois a amamentação da forma correta não causa dor.

Silva et al. (2018) corroboram com os achados da pesquisa enfatizando que as fissuras mamárias, são comumente encontradas logo nos primeiros dias do período puerperal ainda na maternidade, contudo se não houver um suporte emocional e auxílio, é caracterizado como um dos motivos para desistência da amamentação após alta. Tais lesões mamilares decorrentes da amamentação atingem entre 55\% e 100\% das puérperas. (Cirico, Shimoda e Oliveira, 2017).

Em um estudo realizado no Banco de Leite Humano do Maranhão com puérperas, observou-se que 53\% apresentaram dor nos mamilos ao amamentar e 50\% fissuras, configurando como uma problemática para o serviço de saúde, pois ao receber alta do alojamento a probabilidade de ocorrer o desmame precoce é elevado (Castro, 2018).

Além de causar dor, Barbosa et al. (2017) afirmam que pode levar ao sangramento e consequentemente ao desmame precoce se não for realizado uma intervenção com profissional de saúde, pois a puérpera vai achar menos traumático e vai deixar de praticar a amamentação exclusiva. 


\subsection{Contribuições do ALCON/maternidade para resolução das dificuldades.}

No que concerne a contribuição no enfrentamento das dificuldades relacionadas ao período de amamentação dentro do ALCON, nota-se que a maioria recebeu instrução e suporte pela equipe de enfermagem.

" Ainda não melhorou nada, aqui no alojamento eles orientam a tomar bastante líquido, bastante suco e trazem mingau, aí vem faz massagem, elas vêm e fazem estímulo no bico do peito, mas elas falam que só vai sair o bico para fora com a boca do neném puxando" (Azaleia).

"Eles vieram me ensinaram e inclusive me mostraram e me fizeram eu fazer, sempre estavam observando, todas as vezes que vem eles perguntam e sempre tem esse suporte" (Calêndula).

Para Rodrigues et al. (2020) a orientação quanto a amamentação vai muito além do ato de falar, ou seja, ela deve ser observada e auxiliada. É necessário colocar em prática, ajudar a mulher a amamentar instruindo durante o ato.

Silva et al. (2019) referem que outro fato que pode comprometer o AM e o fato de que muitas mulheres não realizam o preparo das mamas para este período, e ainda pelas situações relacionadas aos mamilos, seja por serem invertido bilateralmente, dificuldade na sucção, onde é necessário realizar no AC o acompanhamento deste processo e auxílio.

Lopes et al. (2020) evidenciam que o ALCON é uma continuidade do pré-natal e que deve ser um ambiente que oferte a puérpera apoio, suporte emocional, orientação e incentivo aos cuidados e amamentação, onde a equipe de enfermagem são os profissionais responsáveis por essa prática.

Em um estudo realizado por Moraes et al. (2020) em Salvador na Bahia com puérperas, demonstrou-se que o enfermeiro é o profissional responsável por orientar durante a estadia no ALCON, pois o mesmo é quem presta a assistência direta a paciente no período de internação.

Para Rocha et al. (2018) o enfermeiro tem papel essencial no momento do puerpério, onde orienta, incentiva, atuando em ações educativas, visando o aleitamento materno exclusivo e a resolução de problemas que surgem no período como por exemplo, pega incorreta, fissuras ou bico invertido.

Barbosa et al. (2017) esclarecem que é imprescindível durante a estadia no ALCON a avaliação visual do enfermeiro durante a mamada e sucção do RN para que possa ser corrigida possíveis falhas no processo da amamentação.

Queiroz et al. (2021) esclarecem que é essencial que o enfermeiro realize dentro do ALCON a educação em saúde e contato direto com as puérperas, demonstrando como é a pega correta, a abertura correta da boca do RN, o apoio corporal e tipos de posições para revezamento nas mamadas. Acredita-se que a Enfermagem seja parte integrante da rede de apoio a amamentação, fortalecendo tal prática.

\section{Conclusão}

O resultado apresentado neste estudo possibilitou a caracterização o perfil obstétrico das puérperas, onde as maiorias encontravam-se na faixa entre 18 e 23 anos, com ensino médio completo, tinham realizado seis ou mais consultas e estavam com IG ente 38 a 40 semanas e a predominância do parto foi por via vaginal. Quanto às orientações recebidas no pré-natal, observou-se predominantemente a lacuna referente aos benefícios da amamentação e possíveis dificuldades que poderão surgir no decorrer deste processo, muitas participantes não souberam elencar os benefícios da amamentação tanto para si mesmo a e ou para o RN, sendo um ponto negativo, e o primeiro contato com a amamentação, foi vivenciado com algumas dificuldades pelas puérperas. 
Outro ponto relevante é sobre o papel do ALCON neste processo de amamentação o suporte ofertado, pela equipe desta unidade, as puérperas contribuem para qualidade de vida do binômio, ao valorizar as preocupações, esclarecendo dúvidas das lactantes, e assim evitando desta o fracasso do aleitamento materno e o desmame precoce.

Destaca-se a importância do suporte profissional, onde é capaz de influenciar as mulheres na decisão de amamentar, sendo necessário o apoio, incentivo, enfrentamento das dificuldades e resoluções.

Uma limitação encontrada neste estudo foi referente as pesquisas qualitativas recentes publicadas em banco de dados, onde constatou-se um quantitativo baixo quando comparado com a magnitude do tema, sendo assim considerado um ponto que dificultou a possibilidade de uma discussão mais abrangente.

Sugere-se ampliar as discussões e fomentar sobre a amamentação durante a fase de pré-natal, onde o enfermeiro durante as consultas na gestação necessita de um olhar direcionado a fase puerperal sobre a importância e prevenção de agravos que podem surgir na fase puerperal, quando continuidade as orientações e suporte durante a sua estadia no ALCON.

Faz-se necessário ampliar as discussões através da realização de novas pesquisas voltadas a esta temática, demonstrando a relevância em adotar educação em saúde desde o pré-natal, aproveitando o momento para orientar não somente sobre a gestação como também a fase puerperal e a amamentação, para que estejam preparadas para esta nova fase e diminuam as chances do desmame precoce relacionados as dificuldades encontradas e ausência de orientações, principalmente em gestantes primíparas.

\section{Referências}

Al-Nuaimi,K., Ali, R., Hatem, F. (2019). The effect pf a breastfeeding educational workshop on clinicians knowledge, atitudes and practices. British Journal of Midwifery.

Alves, F. N., Azevedo, V. M. G. O., Moura, M. R. S., Ferreira, D. M. L. M., Araújo, C. G. A., Rodrigues, C. M. \& Wolkers, P. C. B. (2020). Impacto do método canguru sobre o aleitamento materno de recém nascidos pré-termo no Brasil: uma revisão integrativa. Ciênc. saúde coletiva. Araguari - MG.

Arantes, B. M. N., Szczerepa, S. B., Muller, E. V., Ravelli, A. P. X., Rufino, B. M. \& Borges, P. K. O. (2020). Possibilidades de assistência ao aleitamento materno: um panorama sobre as redes de apoio à amamentação. Braz. Journal of Develop., Curitiba.

Barbosa, G. E. F., Silva, V. B., Pereira, J. M., Soares, M. S., Filho, R. A. M., Pereira, L. B., Pinho, L. \& Caldeira, A. P. (2017). Dificuldades iniciais com a técnica de amamentação e fatores associados a problemas com a mama em puérperas. Revista Paulista de Pediatria. Montes Claros, MG.

Barreto, S. I.,Barreto, S. I., Alves, L. O. B., Souza, C. P. R., Conceição, C. M. S., Linhares, E. O. S. \& Sousa, M. F. (2021). Cuidado De Enfermagem Sobre Amamentação Durante O Pré Natal E Puerpério. Revista Saúde Multidisciplinar.

Brasil, Ministério da Saúde. (2019). Leite materno contém todos os benefícios para a saúde do bebê. Brasília - BR.

Brasil, Ministério da Saúde. (2018). OMS e UNICEF lançam novas orientações para promover aleitamento materno em unidades de saúde de todo o mundo. Brasília - BR.

Beyene, A. M., Liben, M. L. \& Arora, A. (2019). Factors associated with the early termination of exclusive breastfeeding among mother-infant dyads in SamaraLogia, Northeastern Ethiopia. BioMed Central Pediatrics. Ethiopia.

Creswel, J. W. (2014). Investigação qualitativa e projeto de pesquisa: Escolhendo entre cinco abordagens. (3a ed.).

Feitosa, M. E. B., Silva, S. E. O., Silva, L. L. (2020). Aleitamento Materno: causas e consequências do desmame precoce. Research, Society and Development. Teresinha - PI.

Ferreira, A. P. M., Silva, P. C. A., Ferreira, A. G. N., Rodrigues, V. P., Lima, A. B. S., Aroucha, L. A. G. \& Gontijo, P. V. C. (2020). Banco de leite humano: mulheres com dificuldades na lactação. Cogitare enfermagem, Maranhão.

Ferreira, M. G. C., Gomes, M. F. P., Fracolli, L. A. (2018). Aleitamento materno: orientações recebidas por gestantes acompanhadas pela Estratégia Saúde da Família. Revista Atenção em Saúde, 16(55), 36-41.

Guimarães, W. S. G., Parente, R. C. P., Guimarães, T. L. \& Garnelo, L. (2018). Acesso e qualidade da atenção pré-natal na Estratégia Saúde da Família: infraestrutura, cuidado e gestão. Cadernos de Saúde Pública, 34(5).

Gupta, P. M., Perrine, C. G., Chen, J., Elam-Evans, L. D., \& Flores-Ayala, R. (2017). Monitoring the World Health Organization Global Target 2025 for Exclusive Breastfeeding: Experience From the United States. Journal of human lactation: official journal of International Lactation Consultant Association, 33(3), 578-581. 
Lopes, A. A. S., Pereira, A. S., Soares, T. S., Sombra, I. C. N., Casadevall, M. Q. F. C., Castro, T. S. C. \& Maia, J. A. (2020). Percepção das puérperas acerca das orientações de enfermagem quanto ao aleitamento materno. Braz. J. of Develop.

Mayor, M. S. S., Herrera, S. D. S. C., Araújo, M. Q., Santos, F. M., Santos, F. M., Arantes, R. V. \& Oliveira, N. A. (2018). Avaliação dos indicadores da assistência pré-natal em unidade de saúde da família, em um município da Amazônia Legal. Revista Cereus, 10(1), 91-100.

Mesquita, N. S., Rodrigues, D. P., Monte, A. S., Ferreira, A. L. A., Manguinho, C. P. C. \& Brandão, J. C. (2019). Perceptions of puérperas about nursing care received in the immediate post-breastfeeding / Percepções de puérperas acerca do cuidado de enfermagem recebido no pós-parto imediato. Revista de Pesquisa: Cuidado é Fundamental Online.

Minayo, M. C. S. (2014). Fundamentos de Pesquisa em Enfermagem: Avaliação de evidências para a prática da enfermagem. (7a ed.), Artmed.

Monteiro, L. S. (2017). Razões maternais para o desmame precoce em uma unidade básica de saúde no município de São Bernardo - MA.

Moraes, I. C., Sena, N. L., Oliveira, H. K. F., Albuquerque, F. H. S., Rolim, K. M. C., Fernandes, H. I. V. M., Silva, N. C. (2020). Perceção sobre a importância do aleitamento materno pelas mães e dificuldades enfrentadas no processo de amamentação. Revista Enfermagem Ref. Coimbra.

Moreira, A. C. N., Perillo, A. L. P., Silva, I. F., Oliveira, J. Z. F. \& Moreira, G. S. (2019). Os benefícios da amamentação exclusiva na vida e saúde das crianças e sua genitora Souza. Pesquisa Unifimes. Minas Gerais.

Queiroz, V. C., Andrade, S. S. C., Cesar,E. S. R., Brito, K. K. G., Costa, C. B. A., Oliveira, S. H. S. (2021). Conhecimentos, atitudes e práticas sobre aleitamento materno entre puerperas em alojamento conjunto. Revista de Enfermagem do Centro oeste mineiro.

Ribeiro, S. C. S. S., Rocha, R. B. S., Jacob, L. M. S., Jorge, H. M. F., Mafetoni, R. R. \& Pimenta, C. J. L. (2018). Atividade educativa para a promoção do cuidado com o recém-nascido. Saúde e Pesquisa, Ceará.

Rodrigues, C. F., Poblete, M., Lipinski, J. \& Zamberlan. (2020). Práticas atuais de amamentação na primeira hora de vida em uma maternidade de risco habitual. Revista Eletrônica Acervo Saúde, 2020.

Rocha, N. F. F., Ferrreira, J. (2020). A escolha da via de parto e a autonomia das mulheres no Brasil: uma revisão integrativa. Saúde Debate. Rio De Janeiro, v. 44, n. 125 , p. $556-568$.

Rocha, A. L. A.; Gois, F. G. B.; Pereira, F. M. V.; Moraes, J. R. M. M.; Barcia, L. L. C. \& Silva, L. F. (2018). O processo de ensino-aprendizagem de puérperas nutrizes sobre aleitamento materno. Revista Cuida.

Santos, A. C., Meireles, C. P. (2021). A importância da amamentação exclusiva nos seis primeiros meses de vida e o papel da enfermagem. Revista Coleta Científica.

Santos, E. M. S., Silva, L. S., Rodrigues, B. F. S., Amorim, T. M. A. X., Silva, C. S., Borba, M. C. \& Tavares, F. C. L. P. (2019). Avaliação do Aleitamento materno em crianças até dois anos assistidas na atenção básica do Recife, Ciência e Saúde Coletiva. Pernambuco, Brasil.

Sardinha, D. M., Maciel, D. O., Gouveia, S. C., Pamplona, F. C., Sardinha, L. M., Carvalho, M. S. B. \& Silva, A. G. I. (2019). Promoção do Aleitamento materno na assistência pré-natal pelo enfermeiro. Revista de Enfermagem UFPE Online, Recife, 13(3), 852-857.

Severino, A. J. (2016). Metodologia do trabalho científico. (24a ed.), Cortez.

Silva, D. D. L., Pacheco, E. S., Silva, V. R., Lima, C. S. O., Lima, E. F. S., Carvalho, V. S., Ribeiro, M. L., Lima S. D. S., Valadares, C. B. \& Souza, A. R. R. (2021). Principais dificuldades vivenciadas por primíparas no cuidado ao recém-nascido. Revista Eletrônica Acervo Saúde.

Silva, Y. J. A., Damasceno, A. C., Pontes, C. D. N., Correa, M. Q. Gurjão, H. H. R., Lima, I. G., Costa, F. B., Carvalho, R. C. \& Nascimento, R. S. (2019). Dificuldades no aleitamento materno na maternidade da fundação santa casa de misericórdia do Pará e o apoio do banco de leite. Revista Eletrônica Acervo Saúde, Pará.

Silva, J. L. P. S., Pereira, F. M. P. L., Barros, A. A., Souza, A. G., Alves, D. S. \& Andrade, P. O. N. (2018). Fatores associados ao aleitamento materno na primeira hora de vida em um hospital amigo da criança. Texto \& Contexto - Enfermagem, 27(4).

Souza, E. F. C., Oliveira, A. A. P., Shimo, A. K. K. (2020). Efeito de uma intervenção educativa para o aleitamento materno: ensaio clínico randomizado. Rev. Latino-Am. Enfermagem.

Skelton, K. R., Evans, R. Lachenaye, J., Amsbary, J., Wingate, M. \& Talbott L. (2018). Exploring Social Media Group Use Among Breastfeeding Mothers: Qualitative Analysis. JMIR Pediatr Parent.

Queiroz, V. C., Andrade, S. S. C., Cesar, E. S. R., Brito, K. K. G., Costa, C. B. A., Oliveira, S. H. S. (2021). Conhecimentos, atitudes e praticas sobre aleitamento materno entre puerperas em alojamento conjunto. Revista de Enfermagem do Centro Oeste Mineiro.

Vieira, G. M., Moraes, T. B., Lima, E. F. A., Pontes, M. B., Brandão, M. A. G. \& Primo, C. C. (2017). Nursing protocol for assistance to women in lactation process Protocolo de enfermagem para assistência à mulher em processo de lactação. Revista de Pesquisa: Cuidado é Fundamental Online.

Volpato, G. L. (2015). Guia prático para a redação científica. Best Writing. 